\title{
Avaliação dos solos e das águas nas áreas de influência de disposição de resíduos sólidos urbanos de Humaitá, Amazonas
}

\author{
Soil and water assessment in the areas of influence \\ of urban solid waste disposal of Humaitá, Amazonas
Benone Otávio Souza de Oliveira', Carlos Alberto Franco Tucci², Afrânio Ferreira Neves Júnior ${ }^{3}$, Aldecy de Almeida Santos ${ }^{4}$

\begin{abstract}
RESUMO
Asáreas utilizadas para disposição de resíduos sólidos urbanos - normalmente representados pelos "lixões" - são focos potenciais de poluição, influenciando negativamente na qualidade de vida, saúde humana e ambiental nas regiões sob sua influência. O objetivo deste estudo foi avaliar as alterações no solo e da água na área de disposição de resíduos sólidos urbanos de Humaitá, Amazonas. O estudo foi realizado em solo de mata nativa, campo natural e na área de disposição de resíduos sólidos, e em curso dáguas próximos à área de disposição de resíduos sólidos. Os baixos teores de argila encontrados no solo da área de estudo o torna inadequado para disposição de resíduos sólidos. Os teores de metais pesados no solo estão dentro dos limites permitidos pela legislação. E na água, apenas o ferro encontra-se acima dos limites permitidos. O índice de qualidade da água mostrou-se bom.
\end{abstract}

Palavras-chave: lixão; contaminação do solo; degradação ambiental; qualidade da água.

\begin{abstract}
The areas used for disposal of urban solid waste - usually represented by the "dumps" - are potential sources of pollution, negatively influencing the quality of human life and environmental health in the regions under their influence. The aim of this study was to evaluate changes in soil and water in the disposal area of the urban solid waste of Humaitá, Amazonas, Brazil. The study was conducted on soil of native forest, natural field and in the solid waste disposal area, as well as in the water courses near the area of solid waste disposal. The low clay levels found in the soil of the study area do not make it suitable for solid waste disposal. The levels of heavy metals in soil are within the limits allowed by law. And only iron in the water is above the limits allowed. The index of quality of water was good.
\end{abstract}

Keywords: dump; soil contamination; environmental degradation; water quality.

\section{INTRODUÇÃO}

$\mathrm{Na}$ atualidade, um dos maiores problemas e desafios enfrentados pelas cidades brasileiras está relacionado com a geração, coleta e destinação dos resíduos sólidos. Tal problema aumenta com o crescimento populacional e pelo alto índice de consumo de bens industrializados (CRUZ, 2006). O município de Humaitá, Amazonas, não difere das diversas cidades brasileiras, pois os resíduos sólidos gerados nessa região são destinados diretamente para um lixão a céu aberto (OLIVEIRA, 2010).

Os lixões a céu aberto e suas adjacências sofrem vários problemas ambientais e sanitários, tais como poluição dos mananciais, contaminação

do ar e do solo, presença de animais (ratos e urubus), poluição visual, dificuldade para navegação aérea, proliferação de vetores, odor e catadores (MONTEIRO et al. 2001), sendo provenientes da destinação de grandes quantidades de resíduos contaminados com substâncias químicas, potencialmente tóxicas, carcinogênicas ou mutagênicas, fatos esses que podem influenciar o bem-estar da população (ACCIOLY \& SIQUEIRA, 2000).

Os elementos potencialmente tóxicos como chumbo $(\mathrm{Pb})$, mercúrio ( $\mathrm{Hg})$, cádmio (Cd), arsênio (As), níquel (Ni) e cromo (Cr) estão presentes em diversos tipos de resíduos levados para os lixões a céu aberto, sendo encontrados em: lâmpadas, pilhas, baterias, produtos farmacêuticos, 口-

'Mestre pela Universidade Federal do Amazonas (UFAM). Professor Auxiliar de Ensino do Instituto de Educação, Agricultura e Ambiente da UFAM - Humaitá (AM), Brasil. 2Doutor pela Universidade Federal de Viçosa (UFV). Professor Titular do Departamento de Engenharia Agrícola e Solos da UFAM - Manaus (AM), Brasil.

${ }^{3}$ Doutor pela Universidade de São Paulo (USP). Professor Adjunto IV do Centro de Educação à Distância da a Faculdade de Ciências Agrárias da UFAM - Manaus (AM), Brasil. ${ }^{4}$ Doutor pela Universidade Federal de Pernambuco (UFPE). Professor Adjunto da Faculdade de Arquitetura, Engenharia e Tecnologia. Departamento de Engenharia Sanitária e Ambiental da Universidade Federal de Mato Grosso (UFMT) - Cuiabá (MT), Brasil.

Endereço para correspondência: Benone Otávio Souza de Oliveira - Rua 29 de agosto, 786 - Centro - 69800-000 - Humaitá (AM), Brasil - E-mail: engambiental87@hotmail.com Recebido: 09/04/14 - Aceito: 05/02/16 - Reg. ABES: 133274 
diversos componentes eletrônicos e outros (MUNÕZ, 2002), sendo indicativos da poluição dos corpos d'água e da contaminação do solo na área de disposição de resíduos sólidos urbanos de Humaitá, Amazonas.

O lixão de Humaitá está localizado no km 10 à margem esquerda da rodovia BR 319, sentido Humaitá-Porto Velho. Por não ter sido realizado estudo técnico para escolha da área, antes de sua instalação, e por não haver infraestrutura sanitária capaz de evitar os danos consequentes da disposição de 11 toneladas diárias de resíduos sólidos, que são coletados em caminhões basculantes, sem nenhum tipo de separação(OLIVEIRA, 2010), fez-se necessária a avaliação dos níveis de metais pesados e estrutura do solo e da água.

A avaliação dos parâmetros físicos e químicos do solo e dos parâmetros físicos, químicos e bacteriológicos da água servirão de subsídios para:

1. elaborar e adequar o plano de gerenciamento de resíduos sólidos;

2. subsidiar informação para um plano de recuperação de áreas degradadas;

3. propiciar benefícios ambientais e sociais;

4. minimizar os impactos ambientais, bem como atender a todas as exigências da nova Política Nacional de Resíduos Sólidos, Lei no 12.305 (BRASIL, 2010).

Diante das argumentações, este trabalho tem como objetivo avaliar o nível de contaminação do solo e da água na área de disposição de resíduos sólidos urbanos de Humaitá, Amazonas.

\section{METODOLOGIA}

\section{Local de estudo}

O local de estudo compreende uma área de 2,5 ha utilizada há 20 anos para disposição de resíduos sólidos (lixão) e áreas adjacentes, que constituem

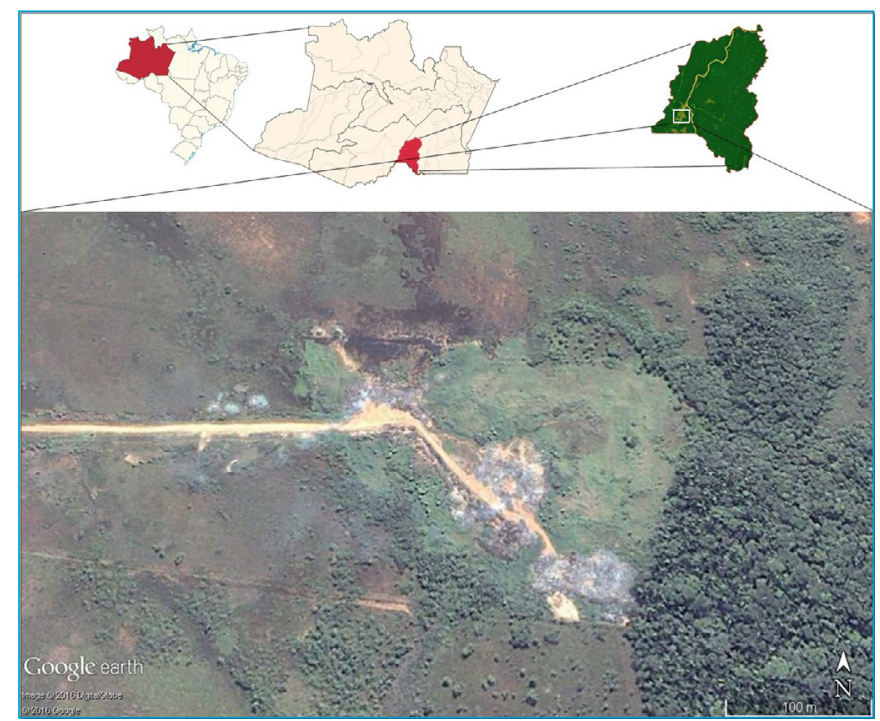

Figura 1 - Área de disposição de resíduos sólidos urbanos no município de Humaitá, Amazonas. três diferentes tipos de cobertura (Figura 1). O local está localizado no km 10 da Rodovia BR 319, no município de Humaitá, entre as coordenadas 07³3'44,03” S e 6304'5,95” W. O município contém aproximadamente 51.320 habitantes, segundo o Instituto Brasileiro de Geografia e Estatística (IBGE, 2015), e situa-se na região sul do estado do Amazonas.

\section{Amostragem das coberturas e análise do solo}

A amostragem de solo foi realizada em 1 ha de superfície dentro das diferentes coberturas, a saber: disposição de resíduos sólidos (D), campo natural (C) e mata nativa (N). Cada cobertura foi subdividida em quatro quadrantes de 50 x $50 \mathrm{~m}$. A seguir, uma breve descrição das coberturas:

1. Área de disposição (D): área que recebe 11 toneladas diariamente de resíduos sólidos urbanos.

2. Mata nativa $(\mathrm{N})$ : área utilizada como referência, composta por fragmento de floresta nativa localizada próxima à área de disposição de resíduos.

3. Campo natural (C): área de campos naturais adjacente à área de disposição de resíduos sólidos.

Para a determinação das propriedades físicas do solo (densidade do solo, porosidade total, microporosidade, macroporosidade, umidade e resistência do solo à penetração de raízes), uma amostra com estrutura indeformada foi coletada dentro de cada quadrante, nas profundidades de $0-5,5-10$ e de $10-20 \mathrm{~cm}$, utilizando anéis metálicos de aproximadamente $5 \times 5 \mathrm{~cm}$.

A análise granulométrica foi realizada utilizando-se o método da pipeta, com solução de $\mathrm{NaOH} 0,1$ mol.L $\mathrm{L}^{-1}$ como dispersante químico. A fração argila foi separada por sedimentação, a areia grossa e fina por tamisação, e o silte calculado por diferença, seguindo a metodologia proposta pela Empresa Brasileira de Pesquisa Agropecuária (EMBRAPA, 1997). Para a determinação da classe textural, utilizou-se o triângulo textural (SANTOS et al., 2005). Densidade do solo, porosidade total, microporosidade e macroporosidade do solo foram determinadas pelo método do anel volumétrico e da mesa de tensão (EMBRAPA, 1997), e a resistência do solo à penetração foi medida conforme os procedimentos descritos em Tormena et al. (2007).

Nas coberturas denominadas D, N e C, um total de 5 amostras de solo foi retirado de cada quadrante (SANTOS et al., 2005) nas profundidades de 0 - 20 e 20 - $40 \mathrm{~cm}$ para a formação de uma amostra composta, utilizada para avaliação das propriedades químicas do solo: $\mathrm{pH}$ em água e $\mathrm{KCl}$, cálcio, magnésio, alumínio, potássio e fósforo disponíveis, acidez potencial $(\mathrm{H}+\mathrm{Al})$, utilizando-se metodologia proposta pela EMBRAPA (1997). O carbono total foi determinado pelo método de Walkley-Black modificado por Yeomans e Bremner (1988).

A digestão do solo para determinação dos metais pesados foi realizada conforme $6010 \mathrm{C}$ (EPA, 2000) e a leitura, em espectrometria de emissão atômica com plasma indutivamente acoplado. A interpretação 
foi realizada com base na Resolução n ${ }^{\circ} 420$ do Conselho Nacional do Meio Ambiente (CONAMA, 2009) (Tabela 1).

\section{Amostragem e análise de água}

Para a realização da análise da água foram plotados 2 pontos de coleta usando um GPS Garmin Etrex no curso d'água (igarapé), um a

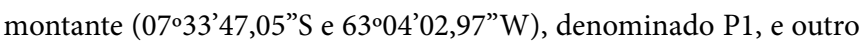

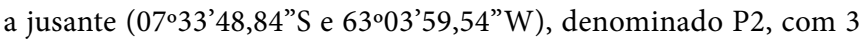
repetições em cada ponto (Figura 2).

As coletas para análises físico-químicas, bacteriológicas e de metais pesados foram realizadas no período chuvoso pelo fato de o curso d'água apresentar característica de intermitência, ou seja, só possui água nesse período. As análises físico-químicas e bacteriológicas seguiram metodologia da American Public Health Association (APHA, 2003). Para as análises de metais pesados, utilizou-se o método espectrometria de emissão atômica com plasma indutivamente acoplado preconizado em 6020 A (EPA, 1998).

Ao final, o índice de qualidade da água (IQA) foi calculado pelo produto ponderado da qualidade da água correspondente às variáveis: oxigênio dissolvido, coliformes termotolerantes, $\mathrm{pH}$, demanda bioquímica de oxigênio, nitrato, fosfato total, temperatura da água,

Tabela 1 - Valores orientados para solos de acordo com a Resolução CONAMA n० 420/2009.

\begin{tabular}{l|c|c|c|c}
\multirow{2}{*}{ Substâncias } & \multirow{2}{*}{ Prevenção } & \multicolumn{3}{|c}{ Intervenção (mg.kg-1) } \\
\cline { 3 - 5 } & & Agrícola Apmax & Residencial & Industrial \\
\hline Arsênio & 15 & 35 & 55 & 150 \\
\hline Cádmio & 1,3 & 3 & 300 & 20 \\
\hline Chumbo & 72 & 180 & 300 & 900 \\
\hline Cromo & 75 & 150 & 300 & 400 \\
\hline Mercúrio & 0,5 & 12 & 36 & 70 \\
\hline
\end{tabular}

Apmax: área de proteção máxima.

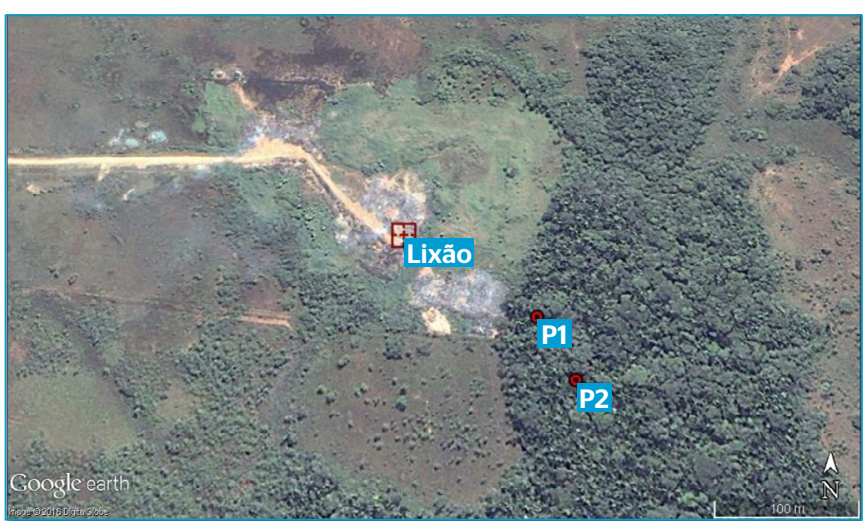

P1: ambiente lêntico que sofre influência direta do lixão a céu aberto; P2: ambinte lótico que sofre influência indireta do lixão a céu aberto.

Fonte: Adaptado de Google Earth (2013).

Figura 2 - Pontos de amostragem de água. turbidez e sólidos totais (CETESB, 2004). Os indicadores de qualidade da água, a partir do IQA, são: ótima $(80 \leq \mathrm{IQA} \leq 100)$, boa $(52 \leq \mathrm{IQA} \leq 80)$, regular $(37 \leq \mathrm{IQA} \leq 52)$, ruim $(20 \leq \mathrm{IQA} \leq 37)$ e péssima $(0 \leq \mathrm{IQA} \leq 20)$ (CETESB, 2004).

Os resultados de análises físico-químicas e bacteriológica foram comparados com a Resolução CONAMA no 357/2005 (Tabela 2).

\section{Análise estatística}

Os dados foram submetidos à análise de variância e comparação de médias, utilizando-se o teste Tukey ao nível de $5 \%$ de probabilidade.

\section{RESULTADOS E DISCUSSÃO}

\section{Propriedades físicas do solo}

Os resultados na análise granulométrica são apresentados na Tabela 3. Os solos das áreas de estudo foram enquadrados na classe textural franco-argilo-siltosa. A granulometria evidenciou que a fração silte é dominante em todas as coberturas estudadas, condição essa que favorece problemas no uso e manejo dos solos, uma vez que tal fração, quando submetida a ações pluviométricas e ciclos alternados de umedecimento e secagem, provoca a criação de uma camada selada, que dificulta a infiltração de água e emergência de

Tabela 2 - Valores orientados para classificação dos corpos d'água de acordo com a Resolução CONAMA n 357/2005.

\begin{tabular}{l|c|c}
\hline Parâmetros & Unidade & VMP \\
$\mathrm{pH}$ & - & 6 a 9 \\
\hline Oxigênio dissolvido & mg.L-1 & $\geq 5$ \\
\hline Condutividade elétrica & HS.cm-1 & - \\
\hline Sólidos totais dissolvidos & mg.L-1 & 500 \\
\hline Cor & Unidade de Hazen* & 75 \\
\hline Temperatura & oC & - \\
\hline Turbidez & UNT & 100 \\
\hline Amônia & mg.L-1 & - \\
\hline Alcalinidade & mg.L-1 & - \\
\hline Nitrito & mg.L-1 & 1 \\
\hline Nitrato & mg.L-1 & 10 \\
\hline Nitrogênio total & mg.L-1 & 3,7 \\
\hline Ortofosfato & mg.L-1 & 0,025 \\
\hline Fósforo total & mg.L-1 & 0,03 \\
\hline Demanda bioquímica de oxigênio & mg.L-1 & 5 \\
\hline Coliformes termotolerantes & NMP/10O ml & 1000 \\
\hline Ferro & Mg/L & 0,3 \\
\hline NN & & \\
\hline
\end{tabular}

UNT: unidade nefalométrica de turbidez; VMP: valores máximos permissíveis pela resolução; *mg Pt-Co/L.

Fonte: CONAMA (2005). 
plântulas (RESENDE et al., 1999) favorecendo, assim, o aumento do escoamento superficial e lixiviação do chorume oriundo da decomposição de resíduos sólidos na área de cobertura D.

Em contrapartida, os baixos teores de argila (Tabela 3), como verificados no solo das coberturas estudadas, contribuem para uma menor capacidade de troca catiônica (CTC) e, consequentemente, menor adsorção de metais (KORF et al., 2008). Segundo Rocca et al. (1993), para fins de disposição de resíduos sólidos urbanos o solo deve conter teores de argila em torno de 56 a 62\%. Com isso, a natureza das coberturas representa inadequação para disposição de resíduos sólidos urbanos.

A condutividade hidráulica do solo saturado nas coberturas apresentou valores mais elevados nos horizontes superficiais com decréscimo em profundidade para todas as coberturas (Tabela 3), com destaque para a cobertura $\mathrm{N}$, corroborando os resultados de Campos et al. (2012) e Martins et al. (2006), os quais afirmam que o fato de a mata nativa apresentar maiores valores proporciona maior permeabilidade aos solos sob a mata, com consequências diretas sobre um maior volume de armazenamento de água em razão de seus solos apresentarem maior profundidade efetiva. Em contrapartida, o tráfego de máquinas na cobertura D causa influência nas propriedades físicas do solo e posição do relevo (MARQUES et al., 2008), consequentemente, causando nessa cobertura alteração da condutividade hidráulica do solo.

A densidade de partículas não foi afetada significativamente, tanto para as coberturas quanto para profundidades (Tabela 3 ), corroborando os valores encontrados por Campos et al. (2012). No entanto, conforme Costa (2004), os valores foram considerados baixos, pois o autor cita valor médio em torno de 2,65 g.cm-3. No entanto, a ausência de grandes diferenças na densidade de partículas entre as coberturas avaliadas ocorreu porque a densidade de partículas depende em grande parte do material de origem; e também apresenta pouca ou nenhuma diferença para uma mesma classe de solo avaliada, justificando a similaridade e

Tabela 3 - Granulometria, condutividade hidráulica saturada e densidade de partículas de um Cambissolo Háplico Tb distrófico típico.

\begin{tabular}{c|c|c|c|c|c} 
Cobertura & $\begin{array}{c}\text { Areia } \\
\left(\mathrm{g} \cdot \mathrm{kg}^{-1}\right)\end{array}$ & $\begin{array}{c}\text { Silte } \\
\left(\mathrm{g} \cdot \mathrm{kg}^{-1}\right)\end{array}$ & $\begin{array}{c}\text { Argila } \\
\left(\mathrm{g} \cdot \mathrm{kg}^{-1}\right)\end{array}$ & $\begin{array}{c}\mathrm{Ks} \\
\left(\mathrm{cm} \cdot \mathrm{h}^{-1}\right)\end{array}$ & $\begin{array}{c}\mathrm{Dp} \\
\left(\mathrm{g}^{\mathrm{cm}} \mathrm{cm}^{-3}\right)\end{array}$ \\
\hline N & 157,46 & 539,62 & 302,92 & $0,066^{\mathrm{a}}$ & $2,41^{\mathrm{a}}$ \\
\hline D & 254,28 & 461,61 & 284,11 & $0,039^{\mathrm{a}}$ & $2,55^{\mathrm{a}}$ \\
\hline C & 115,01 & 577,82 & 307,17 & $0,003^{\mathrm{b}}$ & $2,38^{\mathrm{a}}$ \\
\hline \multicolumn{6}{c}{ Profundidade $(20-40 \mathrm{~cm})$} \\
\hline N & 119,62 & 521,31 & 359,07 & $0,021^{\mathrm{a}}$ & $2,38^{\mathrm{a}}$ \\
\hline D & 168,46 & 485,67 & 345,87 & $0,016^{\mathrm{a}}$ & $2,49^{\mathrm{a}}$ \\
\hline C & 97,15 & 590,15 & 312,7 & $0,014^{\mathrm{a}}$ & $2,39^{\mathrm{a}}$ \\
\hline
\end{tabular}

Ks: condutividade hidráulica saturada; Dp: densidade de partículas; N: mata nativa; D: lixão; C: campo natural; abmédias seguidas da mesma letra minúscula em colunas não diferem pelo teste de Tukey ao nível de 5\% de significância. homogeneidade dessa propriedade nas distintas coberturas e profundidades avaliadas.

A densidade do solo foi estatisticamente superior na cobertura $\mathrm{D}$, quando comparada a $\mathrm{N}$ e $\mathrm{C}$ em todas as profundidades estudadas (Tabela 4). Os valores superiores na cobertura D são provenientes do tráfego de máquinas diário que ocorre no momento da disposição de resíduos sólidos urbanos, corroborando com Ralisch et al. (2008), os quais afirmam que o tráfego de máquinas causa o aumento da densidade do solo. Observa-se ainda que a cobertura $\mathrm{C}$ apresentou valores de densidade intermediários entre a cobertura D e a N. Arshad, Lower e Grossman (1996) afirmam que os valores de densidade do solo encontrados nas coberturas estudadas estão abaixo do nível crítico $\left(1,65 \mathrm{~g} . \mathrm{cm}^{-3}\right)$, o que impõe restrições severas ao crescimento das raízes.

Não foram observadas diferenças estatísticas para a macroporosidade $(\mathrm{MaP})$ nas diferentes coberturas e profundidades (Tabela 4). Entretanto, essas diferenças foram constatadas na microporosidade (MiP). Observou-se redução da MiP na profundidade de $0 \mathrm{a} 5 \mathrm{~cm}$ na cobertura $\mathrm{D}$ e na cobertura $\mathrm{N}$ (Tabela 4). No entanto, foi verificada redução da MaP na cobertura de $\mathrm{D}$, a qual sofre alterações pelo tráfego de máquinas, corroborando Ralisch et al. (2008), os quais afirmam que a movimentação de máquinas reduz a MaP. Em contrapartida, a redução da MiP teve como influência a textura e o teor de carbono orgânico; e pouca influência pelo aumento da densidade do solo ocasionada pelo tráfego de máquinas (NEVES JÚNIOR et al., 2013).

O volume total de poros (VTP) mostrou comportamento inverso à densidade do solo (Tabela 4), ou seja, com o aumento da densidade do solo, o VTP reduziu. Essa redução foi acentuada na cobertura N, profundidade de 0 a $5 \mathrm{~cm}$ (Tabela 4), pois mesmo não tendo sido

Tabela 4 - Atributos físico-hídricos de um Cambissolo Háplico Tb distrófico típico.

\begin{tabular}{c|c|c|c|c|c|c|}
\multirow{2}{*}{ Cobertura } & Ds & MaP & MiP & VTP & U & RSP \\
\cline { 2 - 7 } & $\left({\left.\mathrm{g} . \mathrm{cm}^{-3}\right)}^{-4}\right.$ & \multicolumn{3}{|c|}{$(\%)$} & MPa
\end{tabular}

Profundidade $(\mathrm{O}-5 \mathrm{~cm})$

\begin{tabular}{c|c|c|c|c|c|c}
\hline$N$ & $1,2^{\mathrm{b}}$ & $9,64^{\mathrm{a}}$ & $32,65^{\mathrm{a}}$ & $42,30^{\mathrm{a}}$ & $46,13^{\mathrm{a}}$ & $1,38^{\mathrm{b}}$ \\
\hline $\mathrm{D}$ & $1,50^{\mathrm{a}}$ & $7,7^{\mathrm{a}}$ & $24,99^{\mathrm{b}}$ & $32,6^{\mathrm{b}}$ & $26,62^{\mathrm{b}}$ & $3,51^{\mathrm{a}}$ \\
\hline $\mathrm{C}$ & $1,34^{\mathrm{ab}}$ & $7,71^{\mathrm{a}}$ & $26,25^{\mathrm{b}}$ & $33,96^{\mathrm{b}}$ & $30,60^{\mathrm{b}}$ & $1,64^{\mathrm{b}}$ \\
\hline \multicolumn{5}{l}{} \\
\hline \multicolumn{6}{l}{ Profundidade $(5-10 \mathrm{~cm})$} \\
\hline $\mathrm{N}$ & $1,2^{\mathrm{b}}$ & $8,86^{\mathrm{a}}$ & $30,54^{\mathrm{a}}$ & $39,41^{\mathrm{a}}$ & $44,54^{\mathrm{a}}$ & $1,24^{\mathrm{b}}$ \\
\hline $\mathrm{D}$ & $1,50^{\mathrm{a}}$ & $5,2^{\mathrm{a}}$ & $26,87^{\mathrm{a}}$ & $31,99^{\mathrm{b}}$ & $27,99^{\mathrm{b}}$ & $2,91^{\mathrm{a}}$ \\
\hline C & $1,34^{\mathrm{ab}}$ & $6,71^{\mathrm{a}}$ & $27,78^{\mathrm{a}}$ & $34,49^{\mathrm{ab}}$ & $32,27^{\mathrm{ab}}$ & $1,43^{\mathrm{b}}$ \\
\hline
\end{tabular}

Profundidade $(10-20 \mathrm{~cm})$

\begin{tabular}{c|c|c|c|c|c|c}
\hline$N$ & $1,17^{\mathrm{b}}$ & $7,90^{\mathrm{a}}$ & $30,26^{\mathrm{a}}$ & $38,17^{\mathrm{a}}$ & $31,98^{\mathrm{ab}}$ & $1,30^{\mathrm{b}}$ \\
\hline $\mathrm{D}$ & $1,55^{\mathrm{a}}$ & $4,77^{\mathrm{a}}$ & $26,26^{\mathrm{a}}$ & $31,03^{\mathrm{b}}$ & $26,59^{\mathrm{b}}$ & $3,15^{\mathrm{a}}$ \\
\hline C & $1,36^{\mathrm{ab}}$ & $6,42^{\mathrm{a}}$ & $27,82^{\mathrm{a}}$ & $34,24^{\mathrm{ab}}$ & $31,98^{\mathrm{ab}}$ & $1,30^{\mathrm{b}}$ \\
\hline
\end{tabular}

Ds: densidade do solo; MaP: macroporosidade do solo; MiP: microporosidade do solo; VTP: volume total de poros; U: umidade; RSP: resistência do solo à penetração; N: mata nativa; D: lixão; C: campo natural; abmédias seguidas da mesma letra minúscula em colunas não diferem pelo teste de Tukey ao nível de 5\% de significância. 
observada redução da densidade do solo, quanto à cobertura N, o VTP não apresentou diferença significativa, sendo evidenciado um aumento na compactação e redução dos espaços vazios do solo na cobertura $\mathrm{D}$, enquanto nas coberturas $\mathrm{N}$ e $\mathrm{C}$ evidenciou-se um solo mais poroso e permeável. Dessa maneira, a cobertura D pode propiciar erosão, aumento do escoamento superficial, diminuição de água para as plantas e restrição radicular das culturas (REICHERT; SUZUKI; REINERT, 2007), gerando sérios problemas nas coberturas estudadas, tais como carreamento e percolação do chorume gerados pela decomposição dos resíduos sólidos urbanos e dificuldades para recuperar a área degradada.

$\mathrm{O}$ teor de umidade foi maior na cobertura $\mathrm{N}$ do que nas coberturas $\mathrm{D}$ e C (Tabela 4), pois, à medida que a densidade do solo diminuiu, a umidade aumentou, devido à baixa compressibilidade da água que ocupa a maioria dos poros para condições do grau de saturação próximo de $100 \%$ (DIAS JUNIOR \& ESTANISLAU, 1999). Comparando-se a cobertura $\mathrm{C}$ com a N, observa-se diferença apenas na profundidade de 0 a 5 $\mathrm{cm}$, comportamento semelhante ao VTP (Tabela 4), em consequência do maior contato de fatores intervenientes, tais como chuvas e radiação solar.

Desse modo, a cobertura $\mathrm{N}$ apresentou maior umidade devido à maior infiltração de água no solo e menor evaporação de água decorrente da cobertura do solo por resíduos e pelo dossel que impede que toda água precipitada alcance o solo com alta velocidade. Enquanto que as demais coberturas recebem precipitação direta, a qual propicia erosão e lixiviação, tráfego de máquinas que aumenta a densidade do solo e resistência do solo à penetração, propiciando a diminuição da porosidade total e umidade, e pela radiação solar, que aumenta o processo de evaporação (SALTON \& MIELNICZUK, 1995).

A resistência do solo à penetração foi maior na cobertura $\mathrm{D}$, quando comparada às demais (Tabela 4), ficando evidente que as coberturas $\mathrm{N}$ e C têm pouca limitação ao crescimento radicular de espécies florestais, enquanto a cobertura $\mathrm{D}$ apresentou resistência à penetração superior a 2 $\mathrm{MPa}$. Esse valor é frequentemente assumido como crítico de resistência à penetração, a partir do qual o desenvolvimento radicular das culturas pode ser muito prejudicado (TORMENA: ROLOFF; SÁ, 1998). Essas consequências são decorrentes do intenso tráfego de máquinas no momento da descarga dos resíduos sólidos, diminuindo aeração do solo, o que ocasiona lixiviação e aumento do escoamento superficial. Para tanto, esses valores críticos têm como objetivo principal o sistema de manejo do solo e desenvolvimento radicular das culturas, portanto, os resultados obtidos serão de suma importância na recuperação da cobertura D em caso de uma futura descompactação e recuperação de áreas degradadas.

\section{Propriedades químicas do solo}

Os resultados dos atributos químicos do solo das coberturas e das profundidades são apresentados na Tabela 5. A acidez ativa diminuiu na camada de 0 a $20 \mathrm{~cm}$ nas coberturas $\mathrm{D}$ e na $\mathrm{C}$ quando comparadas à $\mathrm{N}$, uma vez que a mineralização da matéria orgânica e os exsudatos ácidos liberados pelas raízes das plantas contribuíram para aumentar a acidez do solo (BARRETO et al., 2006). A elevada acidez proporciona menor disponibilidade dos nutrientes minerais e torna o ambiente desfavorável para a vida microbiana do solo, responsável pela decomposição da matéria orgânica e fixação de nitrogênio.

Em relação à profundidade de $20 \mathrm{a} 40 \mathrm{~cm}$, a acidez ativa foi estatisticamente igual entre as coberturas D e N (Tabela 5), uma vez que o processo de decomposição e de mineralização levam à produção de substâncias orgânicas de caráter ácido, reduzindo o pH do solo nas camadas superficiais, evidenciando a elevada acidez nas coberturas superficiais e a não diferenciação nas camadas subsuperficiais.

Não foram observadas diferenças estatísticas para a acidez potencial $(\mathrm{H}+\mathrm{Al})$ (Tabela 5), porém os valores são significativamente elevados na cobertura de $\mathrm{N}$, provavelmente em consequência da maior lixiviação promovida pelo intenso regime hídrico associado às melhores condições de drenagem. Em relação ao alumínio trocável (acidez trocável), os teores foram estatisticamente iguais para as coberturas $\mathrm{N}$ e D em

Tabela 5 - Atributos químicos de um Cambissolo Háplico Tb distrófico típico.

\begin{tabular}{|c|c|c|c|c|c|c|c|c|c|c|c|c|c|}
\hline \multirow{2}{*}{ CT } & $\mathrm{pH}$ & $\mathrm{CO}\left(\mathrm{g} \cdot \mathrm{kg}^{-1}\right)$ & $\mathrm{Al}^{3+}$ & $\mathrm{Ca}^{2+}$ & $\mathrm{Mg}^{2+}$ & $\mathrm{H}+\mathrm{Al}$ & $P$ & K & SB & $\mathrm{t}$ & $\mathrm{T}$ & v & $\mathrm{m}$ \\
\hline & $(\mathrm{H} 2 \mathrm{O})$ & $\left(\mathrm{g} \cdot \mathrm{kg}^{-1}\right)$ & \multicolumn{4}{|c|}{$\left(\mathrm{cmol}_{\mathrm{c}} \cdot \mathrm{kg}^{-1}\right)$} & \multicolumn{2}{|c|}{$\left(\mathrm{Mg} \mathrm{dm}^{-3}\right)$} & \multicolumn{3}{|c|}{$\left(\mathrm{cmol}_{c} \cdot \mathrm{kg}^{-1}\right)$} & \multicolumn{2}{|c|}{ (\%) } \\
\hline
\end{tabular}

Profundidade $(0-20 \mathrm{~cm})$

\begin{tabular}{|c|c|c|c|c|c|c|c|c|c|c|c|c|c|}
\hline $\mathrm{N}$ & $3,7^{b}$ & $20^{a}$ & $5,5^{a}$ & $0,0^{a}$ & $0,3^{b}$ & $12^{\mathrm{a}}$ & $1,8^{a}$ & $29^{a}$ & $0,4^{a}$ & $6,0^{a}$ & $12^{\mathrm{a}}$ & $4^{a}$ & $93^{\mathrm{a}}$ \\
\hline D & $4,6^{a}$ & $19^{a}$ & $3,7^{a b}$ & $0,6^{a}$ & $0,3^{b}$ & $7,3^{a}$ & $3,1^{\mathrm{a}}$ & $99^{a}$ & $1,1^{a}$ & $4,8^{a}$ & $8,4^{a}$ & $15^{\mathrm{a}}$ & $76^{a}$ \\
\hline C & $4,8^{a}$ & $2 \mathrm{O}^{\mathrm{a}}$ & $2,3^{b}$ & $1,4^{\mathrm{a}}$ & $0,8^{a}$ & $7,2^{\mathrm{a}}$ & $1,7^{\mathrm{a}}$ & $19^{a}$ & $2,3^{a}$ & $4,6^{a}$ & $9,5^{a}$ & $25^{\mathrm{a}}$ & $49^{b}$ \\
\hline
\end{tabular}

Profundidade $(20-40 \mathrm{~cm})$

\begin{tabular}{|c|c|c|c|c|c|c|c|c|c|c|c|c|c|}
\hline $\mathrm{N}$ & $4,2^{b}$ & $19^{a}$ & $5,5^{a}$ & $0,0^{a}$ & $0,2^{a b}$ & $12^{\mathrm{a}}$ & $1,8^{a}$ & $21^{a}$ & $0,3^{\mathrm{a}}$ & $5,8^{\mathrm{ab}}$ & $12^{\mathrm{a}}$ & $2^{\mathrm{a}}$ & $95^{\mathrm{a}}$ \\
\hline D & $4,7^{\mathrm{ab}}$ & $17^{a}$ & $5,2^{\mathrm{a}}$ & $1,3^{\mathrm{a}}$ & $0,2^{b}$ & $7,7^{\mathrm{a}}$ & $9,2^{\mathrm{a}}$ & $134^{a}$ & $1,8^{a}$ & $7,0^{a}$ & $9,6^{a}$ & $18^{a}$ & $76^{a}$ \\
\hline C & $4,6^{a}$ & $18^{a}$ & $4,2^{\mathrm{a}}$ & $0,3^{a}$ & $0,5^{a}$ & $8,3^{a}$ & $1,6^{a}$ & $16^{a}$ & $0,8^{a}$ & $5,1^{b}$ & $9,1^{\mathrm{a}}$ & $10^{a}$ & $83^{a}$ \\
\hline
\end{tabular}

CO: carbono orgânico; $\mathrm{Al}^{3+}$ : alumínio trocável; $\mathrm{Ca}^{2+}$ : cálcio trocável; $\mathrm{Mg}^{2+}$ : magnésio trocável; H + Al: acidez potencial; P: fósforo; K: potássio; t: capacidade de troca de cátions efetiva; T: capacidade de troca de cátions a pH 7,O; V: saturação por bases; m: saturação por alumínio; CT: cobertura; N: mata nativa; D: disposição; C: campo natural; abmédias seguidas da mesma letra minúscula em colunas não diferem pelo teste de Tukey ao nível de 5\% de significância. 
ambas as profundidades estudadas (Tabela 5). Observou-se redução nos teores de alumínio trocável para a cobertura C (Tabela 5), evidenciando que os valores menores na superfície do solo se dão em decorrência dos maiores teores de carbono orgânico/matéria orgânica (MARTINS et al., 2006). Tal fato está relacionado com a natureza dos sedimentos que formaram o material de origem e com a elevada acidez que condiciona uma solubilidade do alumínio no solo, ou seja, aumentam suas concentrações e provocam deficiência de bases (CAMPOS et al., 2012).

O cálcio e o magnésio trocável, apesar de muito baixos em todas as coberturas estudadas, não apresentaram diferenças estatísticas nas diferentes coberturas e profundidades (Tabela 5), ficando evidente que as deficiências de cálcio trocável nas coberturas são provenientes da lixiviação, erosão hídrica e percolação da água (NOVAIS et al., 2007). Entretanto, houve diferenças para os teores de magnésio, e esse foi maior na cobertura $\mathrm{C}$ (Tabela 5), fato relacionado com a natureza dos sedimentos, material de origem e menor lixiviação desse cátion, corroborando estudo anterior (CAMPOS et al., 2012).

Os teores de fósforo $(\mathrm{P})$ e potássio $(\mathrm{K})$ disponíveis, carbono orgânico (CO), capacidade de troca de cátions a pH 7,0 (T) e percentagem de saturação de base $(\mathrm{V})$ foram iguais nas diferentes coberturas e profundidades estudadas (Tabela 5). Vale salientar que os teores elevados de P disponível na cobertura D corroboram os resultados de ALCÂNTARA et al. (2011), MEDEIROS et al. (2008a) e MEDEIROS et al. (2008b), por motivo do alto índice de resíduos que são dispostos sem nenhum tratamento (matéria orgânica e detergentes). Em contrapartida, diferem de SILVA et al. (2006), que relatam que os teores de $\mathrm{P}$ apresentam comportamento similar à matéria orgânica, ou seja, apresenta tendência decrescente em relação à profundidade, evidenciando a pouca mobilidade e a baixa solubilidade de seus compostos, sobretudo em solos de natureza ácida, enfatizando e confirmando os resultados obtidos nas coberturas $\mathrm{NeC}$.

Os maiores teores de carbono orgânico estão relacionados com os horizontes superficiais, concordando com Alcântara et al. (2011), Medeiros et al. (2008a) e Medeiros et al. (2008b). Esses resultados são atribuídos ao maior acúmulo de materiais orgânicos associado à má drenagem desse ambiente, dificultando a decomposição.

A distribuição do K disponível nas coberturas do solo (Tabela 5) apresentou comportamento semelhante à do $\mathrm{P}$ disponível. Entretanto, ressalta-se que isso se dá em decorrência da sua baixa reatividade com o solo, provocando maior mobilidade. Outro fator importante é que, com os teores de magnésio e cálcio baixos encontrados nas coberturas estudadas, propicia-se a perda de K pela lixiviação, ficando evidente nas coberturas $\mathrm{N}$ e C. Por outro lado, o elevado teor na cobertura D é proveniente do recebimento diariamente de 11 toneladas de resíduos sólidos urbanos (OLIVEIRA, 2010), com grande quantidade de materiais orgânicos.

Para os atributos soma de bases (SB) e saturação por base (V\%) (Tabela 5), os resultados corroboram os de ALCÂNTARA et al. (2011) e CAMPOS et al. (2012), evidenciando que os valores de baixo a médio são em função do alto grau de intemperismo e lixiviação do clima tropical chuvoso.
A capacidade de troca de cátions a pH 7,0 (T) apresentou valores considerados altos (Tabela 5), em consequência da mineralogia dos solos, concordando com CAMPOS et al. (2012) e ALCÂNTARA et al. (2011). Em contrapartida, os valores de saturação por alumínio (m\%) foram entre 49 e 95\% (Tabela 5), valores coerentes com os encontrados por CAMPOS et al. (2012), MARTINS et al. (2006) e ALCÂNTARA et al. (2011).

Foram observadas diferenças significativas na capacidade de troca de cátions efetiva (t) (Tabela 5) apenas para a profundidade de 20 a $40 \mathrm{~cm}$. Tais resultados são provenientes principalmente da lixiviação. Entretanto, Tomé Júnior (1997) ressalta que os teores de matéria orgânica inferiores a $25 \mathrm{~g} \cdot \mathrm{dm}^{-3}$, a partir dessa classificação, podem aferir se os solos das coberturas estudadas apresentam elevada capacidade de retenção de cátions no solo. Os maiores valores foram encontrados na cobertura $\mathrm{N}$, seguida pela cobertura $\mathrm{D}$; consequentemente, a cobertura $\mathrm{N}$ mostrou-se eficiente na manutenção dos nutrientes no ecossistema.

Os teores totais dos metais pesados são apresentados na Tabela 6, evidenciando que os valores encontrados estão dentro dos valores considerados normais em Cambissolos com predominância acentuada do caráter distrófico sugerido por Fadigas et al. (2002), como também apresentaram valores inferiores aos limites estabelecidos pela Resolução CONAMA nº 420/2009.

Quando comparados os resultados das coberturas estudadas, observam-se diferenças de valores, com maiores valores na cobertura $D$, tais como mercúrio, arsênio e chumbo, configurando-se, assim, um alerta para possível contaminação futura por esses metais. Isso se deve à disposição inadequada de resíduos sólidos urbanos, oriundos principalmente de pilhas comuns, lâmpadas fluorescentes, baterias de celulares, compostos eletrônicos, óleos lubrificantes e embalagens de tintas (OLIVEIRA, 2010). Por outro lado, o elevado teor de $\mathrm{Pb}$ no solo pode ser proveniente da baixa mobilidade desse metal no perfil do solo, da sua elevada adsorção na fase sólida (inorgânica e orgânica) e sua capacidade de se acumular na camada superficial do solo (FERNANDES et al., 2011).

De maneira geral, os resultados dos teores totais dos metais, expressos em mg.kg-1 da área de disposição de resíduos sólidos e suas adjacências do município de Humaitá, Amazonas (Tabela 6), foram semelhantes aos estudos de Alcântara et al. (2011) e Pinto Filho et al. (2012).

\section{Análise de água}

A maioria dos parâmetros de qualidade da água, com destaque para turbidez, sólidos totais dissolvidos, nitrito, nitrato, nitrogênio amoniacal e cor, que estiveram inferior tanto no ponto P1 e P2 dos limites máximos permitidos pela Resolução CONAMA no 357/05 para rios de classe II, é apresentada na Tabela 7.

Entretanto, em alguns dos parâmetros foram detectados níveis de contaminação superior aos limites estabelecidos pela Resolução CONAMA n 357/05 (Tabela 7). O IQA dos pontos P1 e P2, conforme CESTESB (2007), apresentaram valores na faixa de 52 e 79, respectivamente, considerando-se a sua descrição como boa. 
Foi possível inferir a influência da área de disposição inadequada de resíduos sólidos urbanos na qualidade da água do curso d'água, pois na amostra coletada em posição montante (P1), a maioria dos parâmetros avaliados apresentaram-se superiores em relação à amostra a jusante (P2). Essas diferenças são oriundas de o ambiente ser lêntico, ou seja, com maior presença de matéria orgânica, podendo causar alterações no ambiente aquático em razão de consumo do oxigênio dissolvido pelos organismos decompositores, assim, o impacto ocorre principalmente pela diminuição da concentração de oxigênio dissolvido disponível na água e não pela presença de substâncias tóxicas (BRAGA et al., 2005).

Analisando a concentração de oxigênio dissolvido, observa-se que no P1 (2,9 mg.L $\left.\mathrm{L}^{-1}\right)$ não se atingiu o mínimo estabelecido pela Resolução CONAMA $\mathrm{n}^{\circ} 357 / 05$, o qual corresponde a $5 \mathrm{mg} . \mathrm{L}^{-1}$, podendo acarretar sérios problemas para a população aquática que vive naquele determinado ambiente.

Em relação ao $\mathrm{pH}$, as amostras apresentaram pequenas variações, contudo essa variação e a predominância do $\mathrm{pH}$ ácido da água podem estar associadas ao $\mathrm{pH}$ ácido do solo e suas diferentes coberturas (Tabela 5). Os resultados apontaram as seguintes condições: nas amostras coletadas, a montante, na estação chuvosa, o pH apresentou-se na faixa de 5,88 e, a jusante, 5,27; isso indica que no período chuvoso existe um carreamento mais acentuado de compostos orgânicos, o que acaba conferindo tais características. Tais resultados são inferiores aos valores estabelecidos pela Resolução CONAMA no $357 / 05$, ficando evidente que o baixo $\mathrm{pH}$ traz prejuízos à saúde da população, como também favorece o desenvolvimento de microrganismos (BRAGA et al., 2005).

O baixo teor de nitrato nos resultados obtidos (0,009 a 1,358 mg.L $\left.\mathrm{L}^{-1}\right)$ indica que a matéria orgânica não foi totalmente oxidada, aferindo que a disposição inadequada de resíduos sólidos urbanos não está causando alterações no curso d'água.

Os valores elevados de $\mathrm{P}$ total $\left(0,048\right.$ a $\left.0,073 \mathrm{mg} . \mathrm{L}^{-1}\right)$ é proveniente da matéria orgânica lançada no curso d'água, o que, segundo

Tabela 6 - Teores de metais pesados de um Cambissolo Háplico Tb distrófico típico.

\begin{tabular}{c|c|c|c|c|c|c|}
\multirow{3}{*}{ Cobertura } & Cádmio & Chumbo & Mercúrio & Cromo & Niquel & Arsênio \\
\cline { 2 - 6 } & \multicolumn{5}{c}{$\left(\mathrm{mg} \cdot \mathrm{kg}^{-1}\right)$} \\
\end{tabular}

Profundidade $(0-20 \mathrm{~cm})$

\begin{tabular}{c|c|c|c|c|c|c}
\hline$N$ & $<0,10$ & 12,50 & $<0,05$ & 17,50 & 1,90 & 2,80 \\
\hline$D$ & $<0,10$ & 15,00 & 0,13 & 23,00 & 2,80 & 2,20 \\
\hline$C$ & $<0,10$ & 11,00 & $<0,05$ & 14,00 & $<1,00$ & $<1,00$ \\
\hline
\end{tabular}

Profundidade $(20-40 \mathrm{~cm})$

\begin{tabular}{c|c|c|c|c|c|c}
\hline$N$ & $<0,10$ & 15,00 & $<0,05$ & 20,00 & 2,70 & 3,20 \\
\hline$D$ & $<0,10$ & 18,00 & 0,06 & 26,00 & 3,50 & 3,80 \\
\hline$C$ & $<0,10$ & 12,50 & $<0,05$ & 16,50 & $<1,00$ & 1,45 \\
\hline$V P$ & 1,30 & 72,00 & 0,50 & 75,00 & 30,00 & 15,00 \\
\hline
\end{tabular}

N: mata nativa; D: disposição; C: campo natural; VP: valor de prevenção.
OLIVEIRA (2010), indica que a maioria dos resíduos sólidos destinados do município de Humaitá são materiais orgânicos. Em contrapartida, as concentrações elevadas de ferro (18,6 a 18,8 mg. $\left.\mathrm{L}^{-1}\right)$ são oriundas das características do solo e do ambiente amazônico, constatando presença abundante de óxidos de ferro e manganês que, nas estações chuvosas nesse caso, apontam para o efeito temporário do excesso de umidade, seguido de um período de aeração que favorece a concentração de tais elementos (ANJOS et al., 2007).

Foi evidente que na área de disposição de resíduos sólidos, algumas características, como relevo, topografia, dentre outras, não influenciaram para que o curso d'água sofresse alterações. Esses resultados diferem de Santana e Barroncas (2007), que observaram concentrações elevadas de metais pesados na água e sedimentos do aterro sanitário de Manaus, Amazonas, causadas pelo chorume lançado nos mananciais das áreas adjacentes.

O IQA dos pontos P1 e P2 foram classificados como bons, segundo CETESB (2004). Apesar de o IQA estar na faixa de classificação, de acordo com as faixas de qualidade (52 a 79), este corresponde ao valor bom. Os principais fatores responsáveis pela redução nos valores do IQA ao longo da avaliação correspondem aos altos níveis de coliformes termotolerantes (1000 a $800 \mathrm{NMP} .100 \mathrm{ml}^{-1}$ ) que, por apresentarem maior peso no cálculo de IQA, contribuem significativamente para redução da qualidade da água. Os altos níveis de coliformes termotolerantes são evidenciados em razão da alta concentração de matéria orgânica e pela lixiviação dos efluentes líquidos.

Tabela 7 - Parâmetros físico-químicos e bacteriológicos da água.

\begin{tabular}{|c|c|c|}
\hline Parâmetros & $\mathrm{P} 1$ & $\mathrm{P} 2$ \\
\hline $\mathrm{pH}$ & 5,88 & 5,25 \\
\hline Oxigênio dissolvido & 2,9 & 5,5 \\
\hline Condutividade elétrica & 198,5 & 7,6 \\
\hline Sólidos totais dissolvidos & 299,00 & 9,04 \\
\hline Cor & 12,72 & 29,90 \\
\hline Temperatura & 27 & 28 \\
\hline Turbidez & 14,1 & 28,0 \\
\hline Amônia & 1,14 & 0,08 \\
\hline Alcalinidade & 35 & 5 \\
\hline Nitrito & 0,025 & $<0,001$ \\
\hline Nitrato & 1,36 & 0,00 \\
\hline Nitrogênio total & 0,998 & 0,991 \\
\hline Ortofosfato & 0,041 & 0,039 \\
\hline Fósforo total & 0,048 & 0,073 \\
\hline Demanda bioquímica de oxigênio & 1,7 & 3,3 \\
\hline Coliformes termotolerantes & 1000 & 800 \\
\hline Ferro & 18,6 & 18,8 \\
\hline
\end{tabular}

P1: ambiente lêntico que sofre influência direta do lixão a céu aberto; P2: ambiente lótico que sofre influênia indireta do lixão a céu aberto. 


\section{CONCLUSÕES}

As análises físicas do solo mostram que a área de disposição de resíduos sólidos apresenta-se compactada.

As análises químicas do solo da área de estudo mostraram que os teores de metais pesados estão abaixo dos limites apontados pela literatura. Todavia, o solo da área demonstra ser quimicamente pobre, exigindo um trabalho de recuperação de áreas degradadas no caso de desativação da área de disposição final de resíduos sólidos urbanos.

Com exceção do Fe, $\mathrm{P}$ total e oxigênio dissolvido, os parâmetros físicos, químicos e bacteriológicos da água encontram-se de acordo com a resolução brasileira para rios de água doce de classe II. Além disso, o IQA apresentou valores na faixa de 52 a 79, o que a classifica como boa.

\section{REFERÊNCIAS}

ACCIOLY, A.M.A \& SIQUEIRA, J.O. (2000) Contaminação química e biorremediação do solo. In: NOVAIS, R.F.; ALVAREZ V.V.C.H.; SCHAEFER, C.E.G.R. (Eds.) Tópicos em Ciência do Solo. Viçosa: Sociedade Brasileira de Ciência do Solo. p.300-307.

ALCÂNTARA, A.J.O.; PIERANGELI, M.A.P.; SOUZA, C.A.; SOUZA, J.B. (2011) Teores de As, Cd, Pb, Cr e $\mathrm{Ni}$ e atributos de fertilidade de Argissolo Amarelo distrófico usado como lixão no município de Cáceres, estado de Mato Grosso. Revista Brasileira de Geociências, v.41, n.3, p.539-548.

ANJOS, L.H.C.; PEREIRA, M.G.; PÉREZ, D.V.; RAMOS, D.P. (2007) Caracterização e classificação de plintossolos no município de Pinheiro-MA. Revista Brasileira de Ciência do Solo, v.31, p.1035-1044.

APHA - AMERICAN PUBLIC HEALTH ASSOCIATION. (2003) Standard methods of the experimentation of water and wastewater. 21th ed. New York: APHA. 1085p.

ARSHAD, M.A.; LOWER, B.; GROSSMAN, B. (1996) Physical tests for monitoring soil quality. In: DORAN, J.W.; JONES, A.J. (Eds.). Methods for assessing soil quality. Madison: Soil Science Society of America. p.123-141.

BARRETO, A.C.; LIMA, F.H.S.; FREIRE, M.B.G.S.; FREIRE, F.J. (2006) Características químicas e físicas de um solo sob floresta, sistema agroflorestal e pastagem no sul da Bahia. Revista Caatinga, v.19, n.4, p.415-425.

BRAGA, B.; HESPANHOL, I.; CONEJO, J.G.L.; BARROS, M.T.L.; SPENCER, M.; PORTO, M.; NUCCI, N.; JULIANO, N.; EIGER, S. (2005) Introdução à engenharia ambiental. 2. ed. São Paulo: Prentice Hall. 305p.

BRASIL. (2010) Lei no 12.305, de 2 de agosto de 2010. Institui a Política Nacional de Resíduos Sólidos; altera a Lei no 9.605, de 12 de fevereiro de 1998; e dá outras providências. Disponível em: <http://www.planalto.gov.br/ ccivil_O3/_Ato2007-2010/2010/Lei/L12305.htm>. Acesso em: 27 mar. 2013.

CAMPOS, M.C.C.; RIBEIRO, M.R.; SOUZA JÚNIOR, V.S.; RIBEIRO FILHO, M.R.; ALMEIDA, M.C. (2012) Topossequência de solos na transição Campos Naturais-Floresta na região de Humaitá, Amazonas. Acta Amazônica, v.42, n.3, p.387-398.

CETESB - COMPANHIA DE TECNOLOGIA DE SANEAMENTO AMBIENTAL. (2004) Relatório de qualidade das águas interiores do estado de São Paulo 2003. São Paulo: CETESB. Disponível em: <http://www.mpsp.mp.br/portal/page/portal/cao_urbanismo_e_meio_
ambiente/biblioteca_virtual/bv_informativos_tecnicos/Relatório\%20 Anual.pdf>. Acesso em: 26 mar. 2012.

CONAMA - CONSELHO NACIONAL DO MEIO AMBIENTE. (2005). Resolução no 357, de 17 de março de 2005. Dispõe sobre a classificação dos corpos de água e diretrizes ambientais para o seu enquadramento, bem como estabelece as condições e padrões de lançamento de efluentes, e dá outras providências. Disponível em: <http://www.mma.gov.br/port/conama/res/res05/res35705.pdf>. Acesso em: 20 out. 2012

CONAMA - CONSELHO NACIONAL DO MEIO AMBIENTE. (2OO9). Resolução no 420, de 28 de dezembro de 2009. Dispõe sobre critérios e valores orientadores de qualidade do solo quanto à presença de substâncias químicas e estabelece diretrizes para o gerenciamento ambiental de áreas contaminadas por essas substâncias em decorrência de atividades antrópicas. Disponível em: <http://www.mma.gov.br/port/ conama/legiabre.cfm?codlegi=620>. Acesso em: 20 set. 2013.

COSTA, J.B. (2004) Caracterização e constituição do solo. 7 ed. Lisboa: Fundação Calouste Gulbenkian. 527p.

CRUZ, L.M. (2006) A questão do lixo na cidade de Avelinópolis GO. Trabalho de Conclusão de Curso - Faculdade de Educação e Ciências Humanas de Anicuns, Anicuns.

DIAS JUNIOR, M.S.; ESTENISLAU, W.T. (1999) Grau de compactação e retenção de água de latossolos submetidos a diferentes sistemas de manejo. Revista Brasileira de Ciência do Solo, v.23, n.1, p.45-51.

EMBRAPA - EMPRESA BRASILEIRA DE PESQUISA AGROPECUÁRIA. (1997). Manual de métodos de análise de solo. 2 ed. Rio de Janeiro: EMBRAPA. 212p.

EPA - UNITED STATES ENVIRONMENTAL PROTECTION AGENCY. (1998). Method 6020A. Inductively coupled plasma - mass spectrometry. Disponível em: <https://www.epa.gov/sites/production/ files/2015-07/documents/epa-6020a.pdf> . Acesso em: 26 ago. 2012.

EPA - UNITED STATES ENVIRONMENTAL PROTECTION AGENCY. (2000). Method 6010C. Inductively coupled plasma-atomic emission spectrometry. Disponível em: <https://www.epa.gov/sites/production/ files/2015-07/documents/epa-6010c.pdf> . Acesso em: 25 ago. 2012.

FADIGAS, F.S.; AMARAL-SOBRINHO, N.M.B. MAZUR; N.; ANJOS, L.H.C.; FREIXO, A.A. (2002) Concentrações naturais de metais pesados em algumas classes de solos brasileiros. Bragantia, v.61, n.2, p.151-159. 
FERNANDES, J.D.; DANTAS, E.R.B.; BARBOSA, J.N.; BARBOSA, E.A. (2011) Estudo de impactos ambientais em solos: o caso da reciclagem de baterias automotivas usadas, tipo chumbo-ácido. Revista Brasileira de Gestão e Desenvolvimento Regional, v.7, n.1, p.231-255.

GOOGLE EARTH. (2013). Disponível em: <http://earth.google.com/>. Acesso em: 10 set. 2014

IBGE - INSTITUTO BRASILEIRO DE GEOGRAFIA E ESTATISTICA. (2013) Estimativas da população. Disponível em: <http://cidades. ibge.gov.br/xtras/temas.php?lang=\&codmun=130170\&idtema=130\& search=amazonas|humaitalestimativa-da-populacao-2015>. Acesso em: 05 mar. 2016.

KORF, E.P.; MELO, E.F.R.Q.; THOMÉ, A.; ESCOSTEGUY, P.A.V. (2008) Retenção de metais em solo da antiga área de disposição de resíduos sólidos urbanos de Passo Fundo-RS. Revista de Ciências Ambientais, v.2, n.2, p.43-60.

MARQUES, J.D.O.; TEIXEIRA, W.G.; REIS, A.M.; CRUZ JUNIOR, O.F.; MARTINS, G.C. (2008) Avaliação da condutividade hidráulica do solo saturada utilizando dois métodos de laboratório numa topossequência com diferentes coberturas vegetais no Baixo Amazonas. Acta Amazônica, v.38, n.2, p.193-206.

MARTINS, G.C.; FERREIRA, M.M.; CURI, N.; VITORINO, A.C.T.; SILVA, M.L. N. (2006) Campos nativos e matas adjacentes da região de Humaitá (AM): atributos diferenciais dos solos. Ciência e Agrotecnologia, v.30, n.2, p.221-227.

MEDEIROS, G.A.; REIS, F.A.G.V.; COSTA, F.B.; BENAGLIA, G.C.; SCOLARI, M.C.; FIORINI, P.A.; MIRANDA, P.A.M.; PASSONI, V. (2008a) Diagnóstico do lixão do município de Vargem Grande do Sul, no estado de São Paulo. Engenharia Ambiental, v.5, n.3, p.1-16.

MEDEIROS, G.A.; REIS, F.A.G.V.; SIMONETTI, F.D.; BATISTA, G.; MONTEIRO, T.; CAMARGO, V.; SANTOS, L.F.S.; RIBEIRO, L.F.M. (2008b) Diagnóstico da qualidade da água e do solo no lixão de engenheiro coelho, no estado de São Paulo. Engenharia Ambiental, v.5, n.2, p.169-186.

MONTEIRO, J.H.P.; FIGUEIREDO, C.E.M.; MAGALHÃES, A.F.; MELO, M.A.F.D.; BRITO, J.C.X.D.; ALMEIDA, T.P.F.D.A; MANSUR, G.L.; ZVEIBIL, V.Z. (Coords.). (2001). Manual de gerenciamento integrado de resíduos sólidos. 15 ed. Rio de Janeiro: IBAM. 200p.

MUÑOZ, S.I.S. (2002) Impacto ambiental na área do aterro sanitário e incinerador de resíduos sólidos de Ribeirão Preto, SP: avaliação dos níveis de metais pesados. Tese (Doutorado) - Universidade de São Paulo, São Paulo.

NEVES JÚNIOR, A.F.; SILVA, A.P.; NORONHA, N.C.; CERRI, C.C. (2O13) Sistemas de manejo do solo na recuperação de uma pastagem degradada em Rondônia. Revista Brasileira de Ciência do Solo, v.37, n.1, p.232-241.

NOVAIS, R.F.; ALVAREZ, V.H.; BARROS, N.F.; FONTES, R.L.; CANTARUTTI, R.B.; NEVES, J.C.L. (Eds.) (2007) Fertilidade do solo. Viçosa: Sociedade Brasileira de Ciência do Solo. 1017p.
OLIVEIRA, B.O.S.D. (2010) Diagnóstico da geração e disposição final dos resíduos sólidos urbanos de Humaitá-AM. Trabalho de Conclusão de Curso - Universidade Federal do Amazonas, Humaitá.

PINTO FILHO, J.L.O;; SOUZA, M.J.J.B.; SANTOS, E.G.; GÊ, D.R.F.; CESAR FILHO, P. (2012) Monitoramento dos teores totais e disponíveis de metais pesados no lixão do município de Apodi-RN. Revista Verde, v.7, n.1, p.141-147.

RALISCH, R.; MIRANDA, T.M.; OKUMURA, R.S.; BARBOSA, G.M.C.; GUIMARÃES, M.F.; SCOPEL, E.; BALBINO, L.C. (2008) Resistência à penetração de um Latossolo Vermelho Amarelo do Cerrado sob diferentes sistemas de manejo. Revista Brasileira de Engenharia Agrícola e Ambiental, v.12, n.4, p.381-384

REICHERT, J.M.; SUZUKI, L.E.; REINERT, D.J. (2007) Compactação do solo em sistemas agropecuários e florestais: identificação, efeitos, limites críticos e mitigação. In: CERETTA, C.A.; SILVA, L.S.; REICHERT, J.M. Tópicos em ciência do solo. Viçosa: Sociedade Brasileira de Ciência do Solo. p. 49-134.

RESENDE, M.; CURI, N.; REZENDE, S.B.; CORREAA, G.F. (1999) Pedologia: base para distinção de ambientes. Viçosa: NEPUT. 367p.

ROCCA, A.C.C.; IACOVONE, A.M.M.B.; BARROTTI, A.J.; CASARINI, D.C.P.; GLOEDEN, E.; STRAUS, E.L. (1993) Resíduos sólidos industriais. 2 ed. São Paulo: CETESB. 234p.

SALTON, J.C. \& MIELNICZUK, J. (1995) Relações entre sistemas de preparo, temperatura e umidade de um Podzólico Vermelho-Escuro de Eldorado do Sul (RS). Revista Brasileira de Ciência do Solo, v.19. n.2, p.313-319.

SANTANA, G.P. \& BARRONCAS, P.S.R. (2007) Estudo de metais pesados (Co, Cu, Fe, Cr, Ni, Mn, Pb e Zn) na Bacia do Tarumã-Açu Manaus (AM). Revista Acta Amazônica, v.37, n.1, p.111-118.

SANTOS, R.D.; LEMOS, R.C.; SANTOS, H.G.; KER, J.C.; ANJOS, L.H. (2005) Manual de descrição e coleta de solos no campo. 5 ed. Viçosa: Sociedade Brasileira de Ciência do Solo. 100p.

SILVA, C.A.; RANGEL, O.J.P.; DYNIA, J.F.; BETTIOL, W.; MANZATTO, C.V. (2006) Disponibilidade de metais pesados para milho cultivado em Latossolo sucessivamente tratado com lodos de esgoto. Revista Brasileira de Ciência do Solo, v.30, n.2, p.353-364.

TOMÉ JUNIOR, J.B. (1997) Manual para interpretação de análises de solo. Guaíba: Agropecuária. 247p.

TORMENA, C.A.; ROLOFF, G.; SA, J.C.M. (1998) Propriedades físicas do solo sob plantio direto influenciadas por calagem, preparo inicial e tráfego. Revista Brasileira de Ciência do Solo, v.22, n.2, p.301-309.

TORMENA, C.A.; ARAÚJO, M.A.; FIDALSKI, J.; COSTA, J.M. (2007) Variação temporal do intervalo hídrico ótimo de um Latossolo Vermelho distrófico sob sistemas de plantio direto. Revista Brasileira de Ciência do Solo, v.31, n.2, p.211-219

YOEMANS, J.C. \& BREMNER, J.M. (1988) A rapid and precise method for routine determination of organic carbon in soil. Communications in Soil Science and Plant Analysis, v.19, n.13, p.1467-1476. 